\title{
A Model for Ferrite/Pearlite Band Formation and Prevention in Steels
}

\author{
P.E.J. RIVERA-DÍAZ-DEL-CASTILLO, J. SIETSMA, and S. VAN DER ZWAAG
}

A model for predicting the conditions under which ferrite/pearlite band formation occurs, and therefore the conditions in which it can be avoided in steels, has been developed. The model requires as input the alloy composition and microchemical segregation wavelength, and provides in turn the homogenization temperature and time in which the alloy should be held in the austenite region for band elimination. The model was applied to three alloys and predicted with accuracy the conditions under which bands were observed to disappear in different investigations from literature. The conditions under which the model can be applied to any alloy are explored.

\section{INTRODUCTION}

FERRITE/PEARLITE and ferrite/martensite banding in steels is a well-known phenomenon that has been recognized for several decades. ${ }^{[1]}$ In the quest for alloys with optimum mechanical properties, the factors influencing the formation of ferrite/pearlite bands have been the object of a great deal of attention. ${ }^{[2]}$ Most of the work has relied on experimental verification of the conditions for band formation as a consequence of isothermal treatment and alloying. ${ }^{[3]}$

A major problem on developing models for predicting band formation has been the lack of quantitative data for the evolution of the austenite-ferrite transformation leading to band formation, and a criterion for the degree of banding. By measuring the degree of anisotropy resulting from an unequal distribution of ferrite and cementite regions, Kop et $a l .{ }^{[4]}$ have provided a method to quantify the degree of banding due to the unequal dilatation behavior in directions normal and parallel to the bands.

The evolution of the austenite $\rightarrow$ ferrite/pearlite transformation leading to banding has recently been studied by Offerman et $a l .{ }^{[5]}$ In an elegant method, they have measured the ferrite fraction formed as a function of time with neutron depolarization (ND) experiments during isothermal annealing, and combined this with electron probe microanalysis (EPMA) measurements for determining the influence of the solute local compositions on band formation. With the aid of a thermochemical database $\left(\right.$ MTData $\left.^{[6]}\right)$, they provided solid evidence for linking band formation with the difference in the nucleation rates of ferrite resulting from the presence of microchemical bands. In their method, however, the driving force for ferrite nucleation was calculated by taking into account the influences of only a limited number of components ( $\mathrm{Fe}, \mathrm{C}$, and $\mathrm{Mn}$ ).

In the present work, a more general thermodynamic/ thermokinetic model is developed for quantifying the formation and prevention of bands as a function of austenitization and transformation temperature and time, and alloy

P.E.J. RIVERA-DíAZ-DEL-CASTILLO, Research Fellow, and S. VAN DER ZWAAG, Professor, are with the Faculty of Aerospace Engineering, Delft University of Technology, 2629 HS Delft, The Netherlands. Contact e-mail: p.rivera@lr.tudelft.nl J. SIETSMA, Associate Professor, is with the Department of Materials Science and Technology, Delft University of Technology, 2628 AL Delft, The Netherlands.

Manuscript submitted March 12, 2003. composition, so that the influences of the process conditions can be tracked down for alloy design and microstructure optimization.

\section{MODEL}

The model has been has been divided in three steps: solidification, diffusion in the austenitic region, and transformation. With regard to the ferrite/pearlite banding phenomenon, the main consequence of the solidification process is the presence of solute concentration gradients across the bands. Therefore, we constrain our description of solidification in terms of obtaining from a thermochemical database ${ }^{[6]}$ approxi mate values for the initial concentration bands present in the alloy.

The diffusion of segregated solutes is mathematically described using a finite differences multicomponent approach, which takes into account carbon cross-diffusion effects. The alloy is then allowed to transform, and the differences in the ferrite nucleation rate across the microchemical bands are calculated at different temperatures. It has been assumed that ferrite/pearlite bands do not form when the difference in local ferrite nucleation rates does not exceed 6 pct. ${ }^{[5]} \mathrm{A}$ more detailed description of the model is given as follows.

\section{A. Solidification Process}

The solidification process occurs as dendrites advance into fresh liquid regions. As the interface advances, some solutes are incorporated in the dendrite whereas others are rejected into the liquid. Such a partition effect will cause the concentration gradients leading to microchemical bands. The present model assumes that the limiting concentration values across bands are those that characterize $\delta$ ferrite when it first forms, and those characterizing the last fraction of liquid when it transforms into solid; i.e., the $\delta$ ferrite composition in the liquid $\rightarrow$ liquid $+\delta$ ferrite transformation and the liquid composition in the liquid $\rightarrow$ solid transformation for each studied alloy.

In an alloy of $\mathrm{k}$ components, there are $2 \mathrm{k}$ of such limiting values of composition across bands; these will be the initial boundary conditions for the diffusion process described in Section B and have been obtained from a phase diagram and thermochemical database (MTData ${ }^{[6]}$ ). 


\section{B. Theory of Diffusion}

Isothermal changes during austenitization of banded steels are a consequence of solute redistribution. This phenomenon can be described with Fick's second law in the multicomponent scenario:

$$
\frac{\partial C}{\partial t}=\nabla \cdot D \nabla C
$$

As suggested by Kirkaldy and Young, ${ }^{[7]}$ Eq. [1] can be numerically solved employing a finite differences algorithm:

$$
\begin{aligned}
C_{\mathrm{k}}^{\mathrm{i}+1, \mathrm{j}}= & C_{\mathrm{k}}^{\mathrm{i}, \mathrm{j}}+\frac{\Delta t}{(\Delta x)^{2}} \sum_{\mathrm{p}=1}^{m}\left[\left(D_{\mathrm{kp}}^{\mathrm{j}+1}-D_{\mathrm{kp}}^{\mathrm{j}}\right)\left(C_{\mathrm{p}}^{\mathrm{i}+1, \mathrm{j}}-C_{\mathrm{p}}^{\mathrm{i}, \mathrm{j}}\right)+\right. \\
& \left.\left(D_{\mathrm{kp}}^{\mathrm{j}}\right)\left(C_{\mathrm{p}}^{\mathrm{i}, \mathrm{j}+1}-2 C_{\mathrm{p}}^{\mathrm{i}, \mathrm{j}}+C_{\mathrm{p}}^{\mathrm{i}, \mathrm{j}-1}\right)\right]
\end{aligned}
$$

where $C_{\mathrm{k}}^{\mathrm{i}+1, \mathrm{j}}$ is the k concentration at time $\mathrm{i}+1$ in node $\mathrm{j}$; $\Delta t$ is the size of the time interval; $\Delta x$ is the distance between nodes; and $D_{\mathrm{kp}}^{\mathrm{j}+1}=\partial D_{\mathrm{k}}^{\mathrm{j}+1} / \partial C_{\mathrm{p}}$ is the variation of $k$ component diffusion coefficient at node $\mathrm{j}+1, D_{\mathrm{k}}^{\mathrm{j}+1}$, with the $\mathrm{p}$ component concentration, $C_{\mathrm{p}}$. When solving Eq. [2], the stability condition

$$
\Delta t \leq 0.25 \frac{(\Delta x)^{2}}{D}
$$

has to be satisfied for nonoscillatory solutions. ${ }^{[8]}$

In the present calculations, the number of nodes was taken as $j=0,1, \ldots, 50$. The presence of isoconcentrate bands was expressed as the boundary conditions

$$
C_{\mathrm{k}}^{\mathrm{i}, \mathrm{j}-1}=C_{\mathrm{k}}^{\mathrm{i}, \mathrm{j}+1}
$$

for $\mathrm{j}=0,50$.

For dilute solutions, Brown and Kirkaldy ${ }^{[9]}$ demonstrated that the interdiffusion coefficients $D_{\mathrm{Ck}}$ can be approximated as

$$
D_{\mathrm{Ck}}=\frac{\partial \mu_{\mathrm{C}} / \partial N_{\mathrm{k}}}{\partial \mu_{\mathrm{C}} / \partial N_{\mathrm{C}}} D_{\mathrm{CC}}
$$

where the subindex $\mathrm{C}$ stands for carbon and $\mathrm{k}$ for a substitutional solute, and $\mu$ and $\mathrm{N}$ stand for chemical potential and mole number, respectively.

The carbon diffusion coefficient in austenite, $D_{\mathrm{CC}}$, is calculated as ${ }^{[10]}$

$$
\begin{aligned}
& D_{\mathrm{CC}}=4.53 \times 10^{-7}\left(1+Y_{\mathrm{C}}\left(1-Y_{\mathrm{C}}\right) 8339.9 T^{-1}\right) \times \\
& \quad \exp \left\{-\left(T^{-1}-2.221 \times 10^{-4}\right)\left(17,767-26,436 Y_{\mathrm{C}}\right)\right\}[6]
\end{aligned}
$$

where $T$ is the austenite temperature in Kelvin, and $Y_{\mathrm{C}}=$ $C_{\mathrm{C}} /\left(1-C_{\mathrm{C}}\right)$ is the site fraction of carbon in the interstitial sublattice. The value of $D_{\mathrm{CC}}$ is in $\mathrm{m}^{2} \mathrm{~s}^{-1}$.

The diffusion coefficients for the substitutional solutes were calculated by ${ }^{[7]}$

$$
D_{\mathrm{kk}}=D_{\mathrm{k} 0} \exp \left\{-Q_{\mathrm{k}} / \mathrm{R} T\right\}
$$

where $\mathrm{R}$ and $T$ are the universal gas constant and austenitization temperature, respectively. The terms $D_{\mathrm{k} 0}$ and $Q_{\mathrm{k}}$ are the $\mathrm{k}$ component diffusivity pre-exponential factor and activation energy for diffusion, whose values are shown in Table I.

In the present model, only the interdiffusion coefficients of $\mathrm{C}$ are taken into account; thus, the interdiffusion coeffi-
Table I. Diffusivity and Activation Energy Values Used for Calculations

\begin{tabular}{lcccl}
\hline $\begin{array}{l}\text { Component } \\
\mathrm{k}\end{array}$ & $\begin{array}{c}\text { Temperature } \\
\text { Range/K }\end{array}$ & $\begin{array}{c}\mathrm{D}_{\mathrm{k} 0} / 10^{-4} \\
\mathrm{~m}^{2} \mathrm{~s}^{-1}\end{array}$ & $\begin{array}{c}\mathrm{Q}_{\mathrm{k}} / 10^{3} \\
\mathrm{~J} \mathrm{~mol}^{-1}\end{array}$ & Reference \\
\hline $\mathrm{Mo}$ & 1173 to 1573 & 25.1 & 323 & 11 \\
$\mathrm{Mo}$ & 1573 to 1613 & 0.036 & 240 & $12-14$ \\
$\mathrm{Cr}$ & 1173 to 1373 & 0.21 & 300 & 15 \\
$\mathrm{Cr}$ & 1373 to 1613 & 10.8 & 292 & 16 \\
$\mathrm{Mn}$ & 1173 to 1573 & 0.178 & 264 & $13,14,17$ \\
$\mathrm{Mn}$ & 1573 to 1613 & 0.486 & 276 & 18 \\
$\mathrm{Si}$ & 1173 to 1613 & 7.0 & 286 & 19 \\
$\mathrm{P}$ & 1173 to 1523 & 0.01 & 183 & 20 \\
$\mathrm{P}$ & 1523 to 1613 & 8.7 & 273 & 21 \\
$\mathrm{~S}$ & 1173 to 1613 & 7.52 & 236 & 22 to 24 \\
\hline
\end{tabular}

cients of the type $D_{\mathrm{ij}}$, where $\mathrm{i} \neq \mathrm{C}$ and $\mathrm{i} \neq \mathrm{j}$ were assumed to be zero.

In applying Eq. [2], it becomes necessary to approach the initial concentration variation between bands by a mathematical function. The nodal concentrations have to satisfy two conditions: (1) in the first time-step, $\mathrm{i}=0$, and the $\mathrm{k}$ concentrations in the initial and final nodes $\left(C_{\mathrm{k}}^{0,0}, C_{\mathrm{k}}^{0,50}\right)$ are those appearing after solidification; and (2) the k average solute concentration across the bands $C_{\mathrm{k}}\{x, t\} *$ must be equal

*Braces are used throughout to indicate the argument of a function. Thus, $C_{\mathrm{k}}\{x, t\}$ means that the composition of component $\mathrm{k}, C_{\mathrm{k}}$, is evaluated at the linear dimension $x$ and time $t$.

to the average alloy concentration; i.e.,

$$
\bar{C}_{\mathrm{k}}=\frac{1}{d} \int_{x=0}^{d} C_{\mathrm{k}}\{x, t\} d x=\frac{1}{50} \sum_{\mathrm{j}=1}^{50} C_{\mathrm{k}}^{\mathrm{i}, \mathrm{j}}
$$

where $d$ is the half-distance between the bands.

Therefore, the initial concentration profile was approximated as a second-order polynomial described by $C_{\mathrm{k}}\{x\}=$ $f_{\mathrm{k} 2} x^{2}+f_{\mathrm{k} 1} x+f_{\mathrm{k} 0}$, where

$$
\begin{gathered}
f_{\mathrm{k} 0}=C_{\mathrm{k}}^{\mathrm{i}, 0} \\
f_{\mathrm{k} 1}=\frac{6}{d}\left[\bar{C}_{\mathrm{k}}-\frac{1}{3}\left(C_{\mathrm{k}}^{\mathrm{i}, 50}-C_{\mathrm{k}}^{\mathrm{i}, 0}\right)-C_{\mathrm{k}}^{\mathrm{i}, 0}\right] \\
f_{\mathrm{k} 2}=\frac{1}{d^{2}}\left[C_{\mathrm{k}}^{\mathrm{i}, 50}-f_{\mathrm{k} 1} d-C_{\mathrm{k}}^{\mathrm{i}, 0}\right]
\end{gathered}
$$

The approximation as a second-order polynomial was chosen for mathematical convenience. Despite this may produce rather sharp concentration profiles around the nodes $C_{\mathrm{k}}^{0,0}, C_{\mathrm{k}}^{0,50}$ (i.e., in the first time-step), these will quickly soften as the computation progresses in further time-steps.

The only concentration profile that was not possible to approximate with a second-order polynomial was that of S. This component is rejected to the liquid phase during solidification, and appears as a concentration spike between bands, as will be shown in Section IV. 
Mass balance must be ensured for subsequent time-steps; thus, for $\mathrm{i} \geq 1$, Eq. [8] must be satisfied. This condition was set by allowing

$$
\begin{aligned}
0 & =\int_{x=0}^{d} \frac{\partial C_{\mathrm{k}}\{x, t\}}{\partial t} d t \cdot d x=\int_{x=0}^{d} \Delta C_{\mathrm{k}}\{t\} \cdot d x \\
& =\sum_{\mathrm{j}=0}^{50}\left(C_{\mathrm{k}}^{\mathrm{i}+1, \mathrm{j}}-C_{\mathrm{k}}^{\mathrm{i}, \mathrm{j}}\right)
\end{aligned}
$$

Equation [12] was imposed by counting all those concentration variations with time larger than zero $\left(S_{\mathrm{LA}}=\right.$ $\left.\sum_{\mathrm{j}}\left(C_{\mathrm{k}}^{\mathrm{i}+1, \mathrm{j}}-C_{\mathrm{k}}^{\mathrm{i}, \mathrm{j}}\right) \Leftrightarrow C_{\mathrm{k}}^{\mathrm{i}+1, \mathrm{j}}-C_{\mathrm{k}}^{\mathrm{i}, \mathrm{j}}>0\right)$ and lower than zero $\left(S_{\mathrm{LO}}=\sum_{\mathrm{j}}\left(C_{\mathrm{k}}^{\mathrm{i}+1, \mathrm{j}}-C_{\mathrm{k}}^{\mathrm{i}, \mathrm{j}}\right) \Leftrightarrow C_{\mathrm{k}}^{\mathrm{i}+1, \mathrm{j}}-C_{\mathrm{k}}^{\mathrm{i}, \mathrm{j}}<0\right)$, and making them equal by using a correction factor $C_{\mathrm{F}}$ such that $S_{\mathrm{LA}}=C_{\mathrm{F}} S_{\mathrm{LO}}$. The value of $C_{\mathrm{F}}$ was typically five orders of magnitude lower than $S_{\mathrm{LA}}$ and $S_{\mathrm{LO}}$.

\section{Ferrite Nucleation and Band Formation Criterion}

In a recent work, Offerman et al. ${ }^{[5]}$ provided evidence showing that the formation of ferrite/pearlite bands depends on the presence of both chemical bands and the isothermal transformation temperature, such a process being governed by the localized nucleation of ferrite grains at different rates across the concentration bands. In the classical nucleation theory, the rate of ferrite nucleation is given by ${ }^{[5]}$

$$
\frac{d N}{d t}=N_{n} \frac{\mathrm{k} T}{\mathrm{~h}} \exp \left\{-\frac{\Delta G^{*} \lambda}{\mathrm{k} T}\right\} \exp \left\{-\frac{Q_{D}}{\mathrm{k} T}\right\}
$$

where $N$ is the number of nuclei, $N_{n}$ is the number of potential nucleation sites, $\mathrm{k}$ is the Boltzmann constant, $\mathrm{h}$ is the Planck's constant, $\lambda$ is a scaling factor, ${ }^{[25]} Q_{D}$ is the activation energy for self-diffusion, and

$$
\Delta G^{*}=\frac{4\left(z_{2} \gamma_{\alpha \gamma}-z_{1} \gamma_{\gamma \gamma}\right)^{3}}{27 z_{3} \Delta G_{v}^{2}}
$$

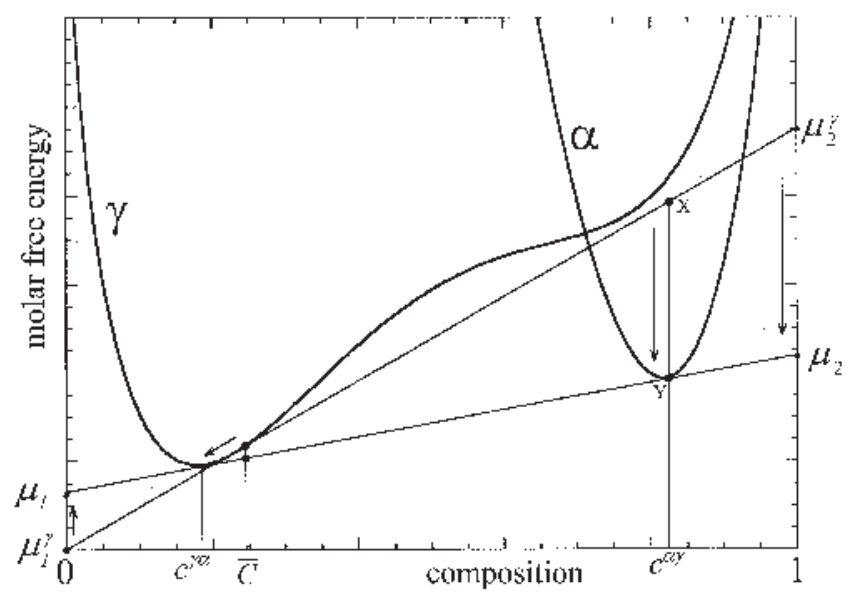

Fig. 1-Molar Gibbs energy for ferrite formation. is the energy barrier for nucleation on austenite/austenite grain boundaries. Equation [14] has been derived for nucleation of ferrite in austenite grains assumed to possess tetrakaidecahedron morphology. ${ }^{[26]}$ In such a model, ferrite nucleation may occur at the boundary, edge, or corner of the austenite grains; $z_{1}, z_{2}$, and $z_{3}$ are geometrical parameters that depend on the type of nucleation site in the austenite grain; for nucleation at the edge of the tetrakaidecahedron, $z_{1}=0.72, z_{2}=1.3$, and $z_{3}=0.096 .^{[5]}$ The driving force for nucleation per unit volume, $\Delta G_{v}$, was calculated for each studied alloy, by taking into account the contributions of its main diffusing components. For a given alloy composition $\bar{C}_{k}$, if $\mu_{\mathrm{k}}^{\gamma}$ is the k component chemical potential of pure metastable austenite, $\mu_{\mathrm{k}}$ is the equilibrium chemical potential of the $\mathrm{k}$ element in ferrite at the transformation temperature, and $C_{\mathrm{k}}^{\alpha \gamma}$ is the equilibrium composition of ferrite nucleating at the transforming temperature, then the molar driving force for nucleation, $\Delta G_{m}$ is given by the distance XY in Figure 1. This can be approximated as

$$
\Delta G_{m}=C_{\mathrm{k}}^{\alpha \gamma} \cdot \mu_{\mathrm{k}}^{\gamma}-C_{\mathrm{k}}^{\alpha \gamma} \cdot \mu_{\mathrm{k}}=C_{\mathrm{k}}^{\alpha \gamma} \cdot\left(\mu_{\mathrm{k}}^{\gamma}-\mu_{\mathrm{k}}\right)
$$

which represents a dot product. The term $\Delta G_{v}$ was approximated by dividing $\Delta G_{m}$ over the ferrite molar volume.

In the present model, the Gibbs energy for ferrite nucleation has been calculated for each of the 51 nodes $(j=0, \ldots, 50)$ at each time-step. Then, it becomes possible to compare the difference between the nucleation rates between two nodes, say, N1 and N2, by using the parameter

$$
\begin{aligned}
r & =\frac{(d N / d t)_{\mathrm{N} 1}-(d N / d t)_{\mathrm{N} 2}}{(d N / d t)_{\mathrm{N} 1}} \\
& =1-\exp \left\{\frac{\lambda}{\mathrm{k} T}\left(\Delta G_{\mathrm{N} 1}^{*}-\Delta G_{\mathrm{N} 2}^{*}\right)\right\}
\end{aligned}
$$

At each time-step, the nodes N1 and N2 have been chosen to provide the maximum value of $r$ through maximizing $\left|\Delta G_{\mathrm{N} 1}^{*}-\Delta G_{\mathrm{N} 2}^{*}\right|$. The critical value of $r$ above which ferrite/ pearlite bands are assumed to form is $r \approx 0.06$ to $0.08 .^{[5]}$

\section{EXPERIMENTAL INPUT}

The three alloys shown in Table II were chosen due to the previous experimental work performed on them. Alloys 1 and 2 were studied by Grange. ${ }^{[27]}$ He reported that for both alloys, microstructural banding is removed by heat treating for 600 seconds between 1588 and $1618 \mathrm{~K}$, and

Table II. Composition of Studied Alloys

\begin{tabular}{lccc}
\hline Component & $\begin{array}{c}\text { Alloy } \\
\text { 1/Wt Pct }\end{array}$ & $\begin{array}{c}\text { Alloy } \\
\text { 2/Wt Pct }\end{array}$ & $\begin{array}{c}\text { Alloy } \\
\text { 3/Wt Pct }\end{array}$ \\
\hline $\mathrm{C}$ & 0.25 & 0.25 & 0.364 \\
$\mathrm{Si}$ & 0.005 & 0.22 & 0.305 \\
$\mathrm{Mn}$ & 1.5 & 1.5 & 0.656 \\
$\mathrm{~S}$ & 0.006 & 0.019 & - \\
$\mathrm{P}$ & 0.015 & 0.015 & 0.014 \\
$\mathrm{Mo}$ & - & - & 0.016 \\
$\mathrm{Cr}$ & - & - & 0.177 \\
$\mathrm{Fe}$ & balance & balance & balance \\
\hline
\end{tabular}


then air cooling, and below that temperature range, the 600 -second treatment was noticeably less effective in removing banding. Offerman et al. ${ }^{[5]}$ studied the alloy $\mathrm{Fe}$ 0.364C-0.305Si-0.656Mn-0.014P-0.021S-0.177Cr-0.016Mo$0.092 \mathrm{Ni}-.226 \mathrm{Cu}-0.017 \mathrm{Sn}$ (wt pct), from which alloy 3 (Table II) contains most of its main components. Offerman reported that after heat treating the alloy for 30 minutes at $1173 \mathrm{~K}$, and cooling to $953,961,975,987,1000,1013$, and $1031 \mathrm{~K}$, and holding there for 4.5 hours for allowing transformation to occur, banding disappeared just for the sample transformed at $953 \mathrm{~K}$.

The concentration ranges after solidification for each alloy, as obtained from MTData, are shown in Table III. These are the initial values for the diffusion process.

\section{RESULTS}

\section{A. Alloy 1}

An additional required input for running the model was the band wavelength; this was estimated as $19.5 \mu \mathrm{m}$ from the micrographs published by Grange. ${ }^{[27]}$ The only fitting parameter is $\lambda$, which was given the value of 0.0015 for optimum results; this value was employed for the three alloys.

For heat treatments at 1173 and $1593 \mathrm{~K}$, the nodal concentration variations with time are shown in Figures 2 and 3, respectively, for each diffusing component.

Figures 2 and 3 show a faster flattening of the concentration profiles as the temperature is increased. The $\mathrm{C}$ reaches equilibrium just within 0.6 seconds in the case of $1593 \mathrm{~K}$ treatment; $\mathrm{Si}$ and $\mathrm{Mn}$, which at $1173 \mathrm{~K}$ show virtually no changes in their concentration profiles after 900 seconds of treatment, will reach an approximately flat profile after 600 seconds at $1593 \mathrm{~K}$; similarly, the flattening of $\mathrm{S}$ and $\mathrm{P}$ concentration profiles is significantly accelerated with the heat treating temperature. A convenient way to compare the relative flattening velocity for each component is by plotting the concentration of each solute in nodes 0 and 50; flattening approximately occurs

Table III. Compositions at the Center of the Bands and Half-Distance between Them for Each Studied Alloy

\begin{tabular}{lccc}
\hline Alloy & Component k & $C_{\mathrm{k}}^{0,0} / \mathrm{Wt}$ Pct & $C_{\mathrm{k}}^{0,50 / \mathrm{Wt} \text { Pct }}$ \\
\hline 1 & $\mathrm{C}$ & 0.0423 & 0.7346 \\
1 & $\mathrm{Si}$ & 0.0027 & 0.0093 \\
1 & $\mathrm{Mn}$ & 1.0903 & 2.0552 \\
1 & $\mathrm{~S}$ & 0.000 & 0.3481 \\
1 & $\mathrm{P}$ & 0.014 & 0.0307 \\
2 & $\mathrm{C}$ & 0.0413 & 0.7269 \\
2 & $\mathrm{Si}$ & 0.1215 & 0.3607 \\
2 & $\mathrm{Mn}$ & 1.0548 & 2.0643 \\
2 & $\mathrm{~S}$ & 0.000 & 1.1372 \\
2 & $\mathrm{P}$ & 0.0141 & 0.0308 \\
3 & $\mathrm{C}$ & 0.061 & 1.040 \\
3 & $\mathrm{Si}$ & 0.177 & 0.550 \\
3 & $\mathrm{Mn}$ & 0.447 & 0.966 \\
3 & $\mathrm{P}$ & 0.013 & 0.031 \\
3 & $\mathrm{Mo}$ & 0.011 & 0.032 \\
3 & $\mathrm{Cr}$ & 0.152 & 0.222 \\
$1,2,3$ & $\mathrm{Fe}$ & bal. & bal. \\
\hline
\end{tabular}

when these concentrations become equal, as shown in Figure 4 for $1593 \mathrm{~K}$.

Figure 4 shows that all components will be characterized by flat concentration profiles after 900 seconds (15 minutes). Furthermore, it reveals that such flattening is attained first by $\mathrm{C}$, approximately one time order of magnitude later by $\mathrm{S}$, and at around 600 seconds by $\mathrm{P}$ and $\mathrm{Si}$, respectively. The Mn is the last component to flatten; this happens after 600 seconds.

With the nodal compositions at different time-steps, it becomes possible to calculate from MTData the nodal Gibbs energy for the $\gamma \rightarrow \alpha$ transformation, both when austenite is the only phase present (point $X$ in Figure 1) and at the equilibrium Gibbs energy (point $\mathrm{Y}$ in Figure 1). The energy difference provides the nodal driving forces through Eq. [15], which are then inserted in Eq. [16] for obtaining the maximum relative differences in nucleation rates across the bands $(r)$. Figure 5 shows the change in $r$ with transformation temperature for samples heat treated for 900 seconds at temperatures ranging between 1173 and $1613 \mathrm{~K}$ as indicated. Consistent with Grange's experiments, ${ }^{[27]}$ Figure 5 reveals that banding disappears when heat treating the alloy at temperatures equal to or larger than $1593 \mathrm{~K}$, if bands are assumed to disappear under values of $r$ between 0.06 and $0.08 .^{[5]}$

Figure 5 and forthcoming plots of the variation of $r$ with transformation temperature display a monotonic increase of $r$ with transformation temperature; this is due to the fact that a lower volume free energy change for the $\gamma \rightarrow \gamma+\alpha$ transformation is present as the difference between austenitization and transformation temperature is reduced. For the same reason, the $r$ plots are shifted upward as austenitization temperature is increased and transformation temperature is kept constant.

Figure 6 shows the variation of $r$ with transformation temperature for an alloy heat treated at $1593 \mathrm{~K}$ for the indicated times. It shows that the nucleation rate parameter $r$ decreases with increasing treating time. If the average values of $r$ are taken into account, $r_{a v}$, the only treating times characterized by $r_{a v} \leq 0.06$ are 600 and 900 seconds.

\section{B. Alloy 2}

For alloy 2, the microchemical band wavelength was taken as $13.9 \mu \mathrm{m} .{ }^{[27]}$ The solute redistribution is shown by plotting the solute concentrations as a function of time for heat treatments at 1173 and $1593 \mathrm{~K}$ in Figures 7(a) and (b), respectively. These figures show that the heat treatment at $1173 \mathrm{~K}$ even for $10^{3}$ seconds is unable to remove microchemical bands, whereas the $1593 \mathrm{~K}$ heat treatment effectively removes them within 600 seconds.

The maximum values of $r$ as a function of transformation temperature for a number of 900-seconds heat treatments is shown in Figure 8, whereas Figure 9 displays the evolution of $r$-transformation temperature curves with time for alloy 2 heat treated at $1593 \mathrm{~K}$. Again, the calculations precisely follow Grange's observations ${ }^{[27]}$ that bands are considered to disappear (with $r \leq 0.06^{[5]}$ ) for heat treating between 1593 and $1613 \mathrm{~K}$ for 600 seconds or more. In fact, shorter times or lower temperatures should be sufficient.

\section{Alloy 3}

The nucleation rate parameter $r$ can be scaled by choosing an appropriate value of $\lambda$ in Eq. [16]. In the previous two 

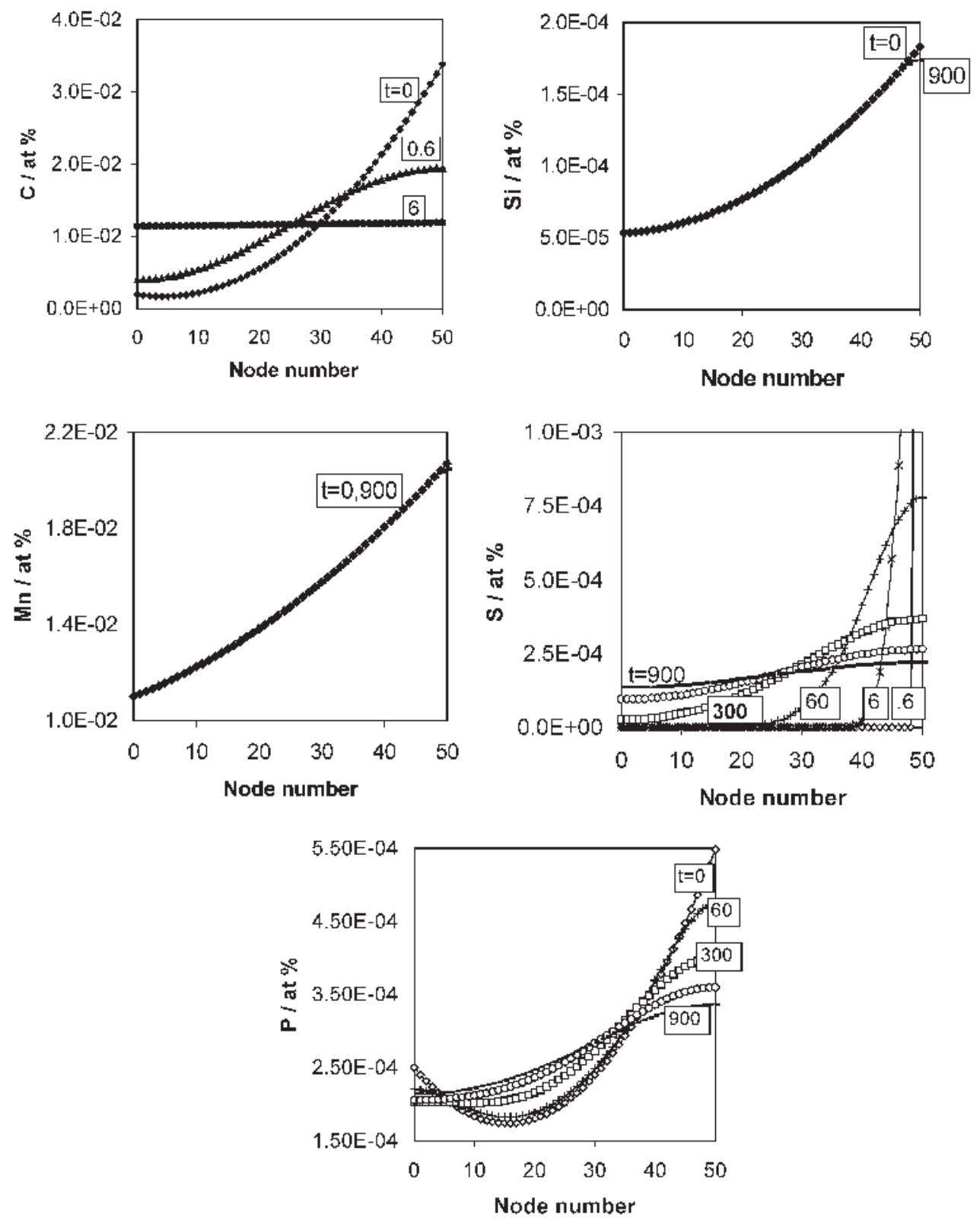

Fig. 2-Local composition changes with time for $1173 \mathrm{~K}$ treatment. Time $(t)$ in seconds.

alloys, it has been seen that the band elimination is coincident with a flattening of the concentration profiles, so it appears that the chosen value of $\lambda=1.5 \times 10^{-3}$ is simply one that produces values of $r \leq 0.06$ at temperatures equal or larger than $1588 \mathrm{~K}$. For testing the accuracy of the present model, the alloy studied by Offerman et al. was selected, since they discovered that bands disappear after a 30-minute heat treatment at $1173 \mathrm{~K}$ (which is expected to be too low as an austenitization temperature) and further transformation at temperatures equal to or lower than $953 \mathrm{~K} .{ }^{[5]}$

Figure 10 shows the solute redistribution as a function of time for a $1173 \mathrm{~K}$ heat treatment. Very small changes are observed after 1800 seconds, apart from $\mathrm{C}$, which reaches a flat equilibrium profile after approximately 100 seconds. The variation of the parameter $r$ with transformation tem- perature is shown in Figure 11; consistent with the observations of Offerman et al., the only transformation temperatures with $r \leq 0.06$ are those lower than or equal to $953 \mathrm{~K}$.

The model was further applied to alloy 3 in order to evaluate if bands can be eliminated by heat treating at $1613 \mathrm{~K}$ for 30 minutes, and then allowing transformation in the range of temperatures between 940 and $1040 \mathrm{~K}$. The results for the concentration profiles flattening are shown in Figure 12, and the variation of $r$ with the transformation temperature is shown in Figure 13. These figures show that although there is a considerable flattening of the concentration profiles of $\mathrm{P}, \mathrm{Cr}$, and $\mathrm{Si}$, and a complete flattening of $\mathrm{C}$, important variations in the concentrations of $\mathrm{Mn}$ and Mo remain; the variations of $r$ with the transformation temperature thus 

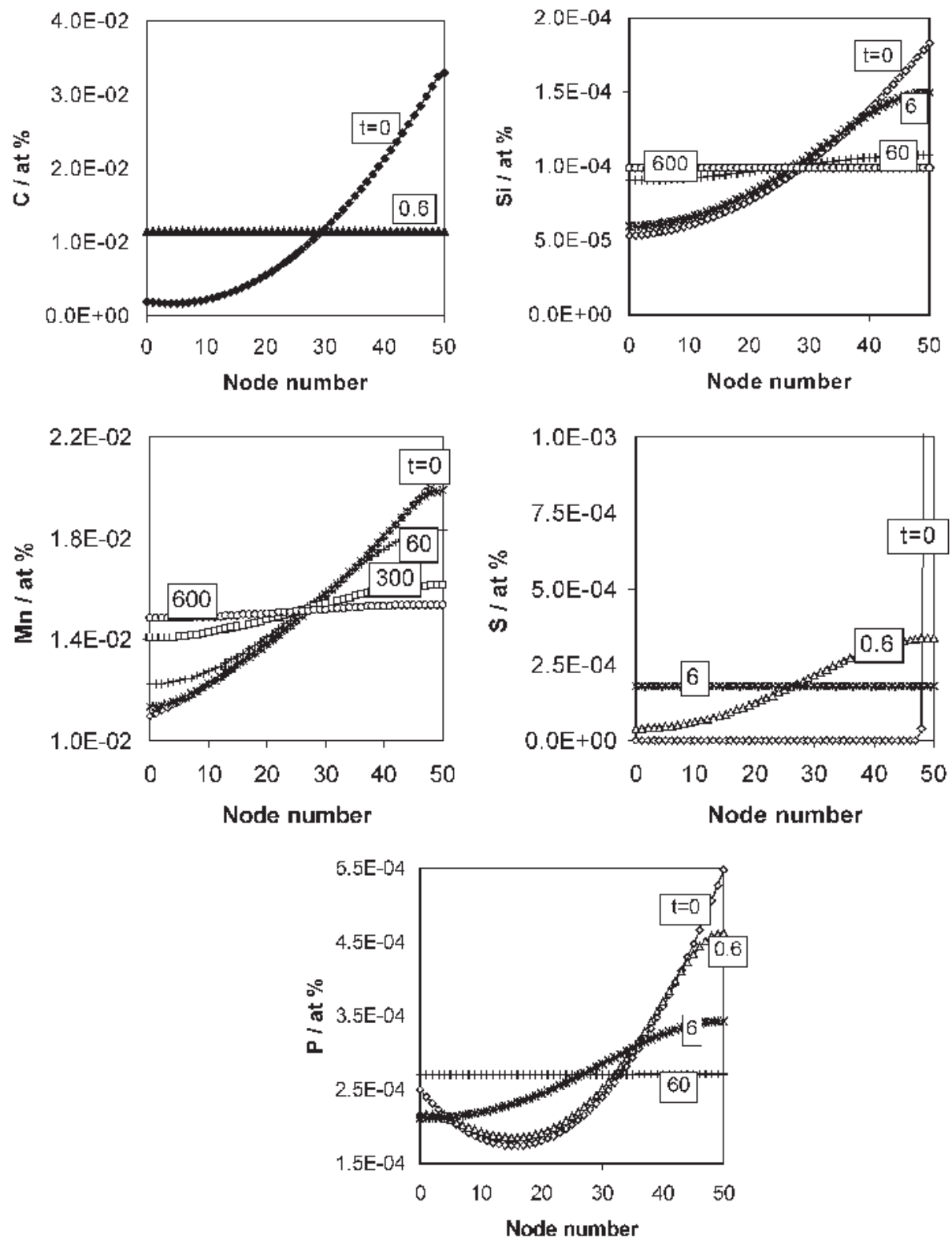

Fig. 3-Local composition changes with time for $1593 \mathrm{~K}$ heat treatment. Time $(t)$ in seconds.

vary only a little as compared to those from the alloy heat treated at $1173 \mathrm{~K}$ (Figure 11).

\section{DISCUSSION}

A model for prediction of the conditions leading to band formation and prevention has been developed. The main input of the model is the alloy composition and the band wavelength. The model was first applied to the alloys studied by Grange, ${ }^{[27]}$ who observed that bands are eliminated after heat treating for 10 minutes or more at temperatures between 1588 and $1613 \mathrm{~K}$. Our calculations show a rapid flattening of the $\mathrm{C}$ concentration profiles and elimination of those related to $\mathrm{Si}, \mathrm{Mn}, \mathrm{S}$, and $\mathrm{P}$ just before 600 seconds of heat treatment. The results show a reduction of $r$ for different transformation temperatures when the heat treatment time and temperature are increased. When Offerman's criterion of band elimination is employed, the model precisely predicts the heat treatment times and temperatures leading to band elimination.

It is natural to expect that the model will predict band elimination in Grange's alloys because bands are expected to disappear at large temperatures and heat treating times due to the solute homogenization leading to minimization of the differences in Gibbs free energy for ferrite formation across the microchemical bands. Offerman's alloy provided a means to test the capability of the model for predicting band elimination at low transformation temperatures and at much lower heat treating temperatures than in Grange's case. The model has even predicted that under Offerman's heat treatment times, it is not possible to eliminate bands even after treating at much higher temperatures $(1613 \mathrm{~K})$; further experimentation is required to prove this. 


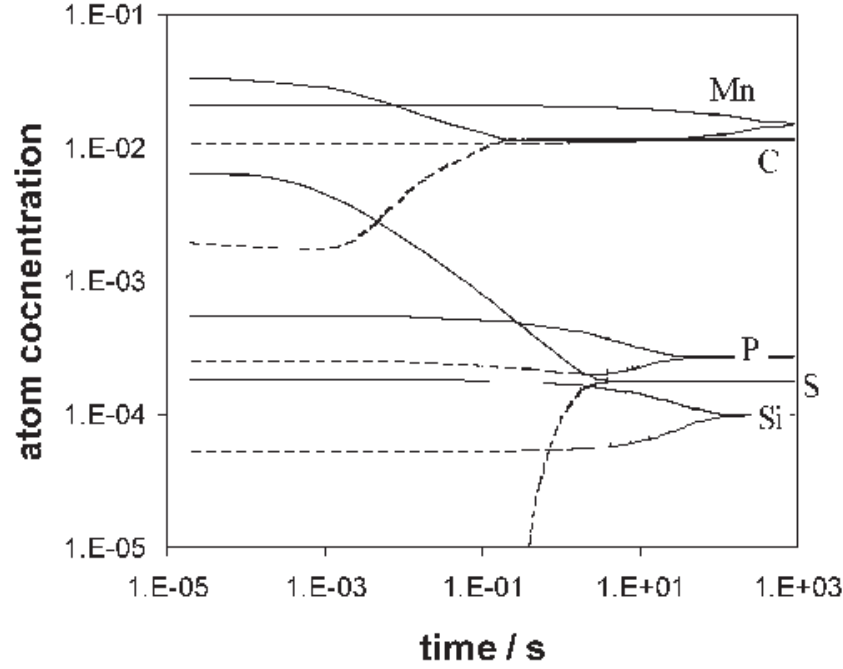

Fig. 4-Component concentrations in nodes 0 (dotted lines) and 50 (solid lines).

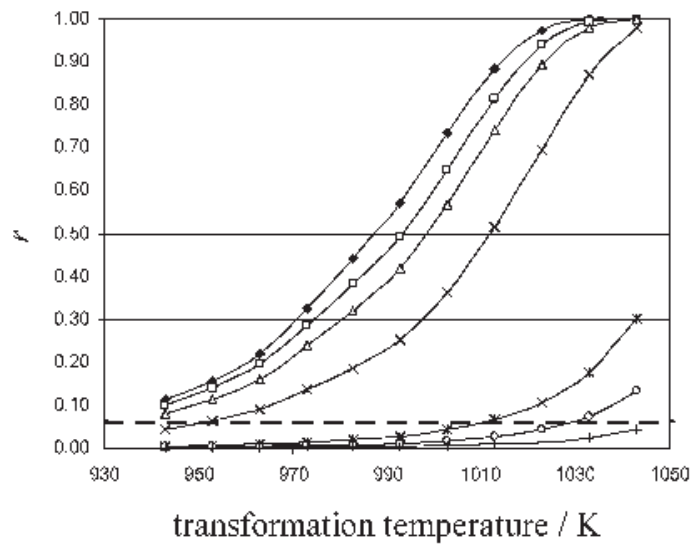

$-1173 \mathrm{k}$

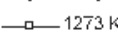

- $-1373 \mathrm{~K}$

$\approx-1473 k$

$\rightarrow-1573 \mathrm{~K}$

$\longrightarrow 1593 \mathrm{~K}$

— $1813 \mathrm{~K}$

- $=0.06$

Fig. 5-Variation of $r$ with transformation temperature for alloy 1 hea treated at the indicated temperatures. The dotted line $(r=0.06)$ represents the limit under which bands disappear. ${ }^{[5]}$

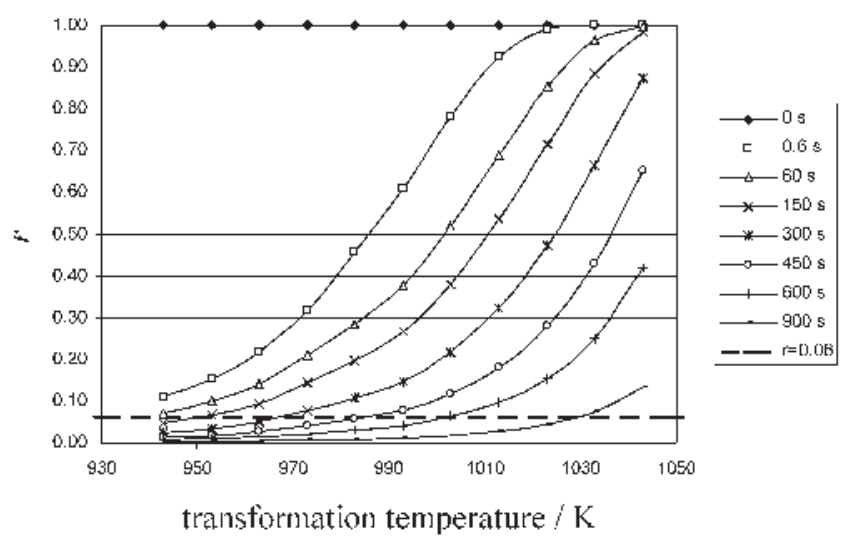

Fig. 6-Variation of $r$ with the transformation time for alloy 1 heat treated at $1593 \mathrm{~K}$. The dotted line $(r=0.06)$ represents the limit under which bands disappear. ${ }^{[5]}$

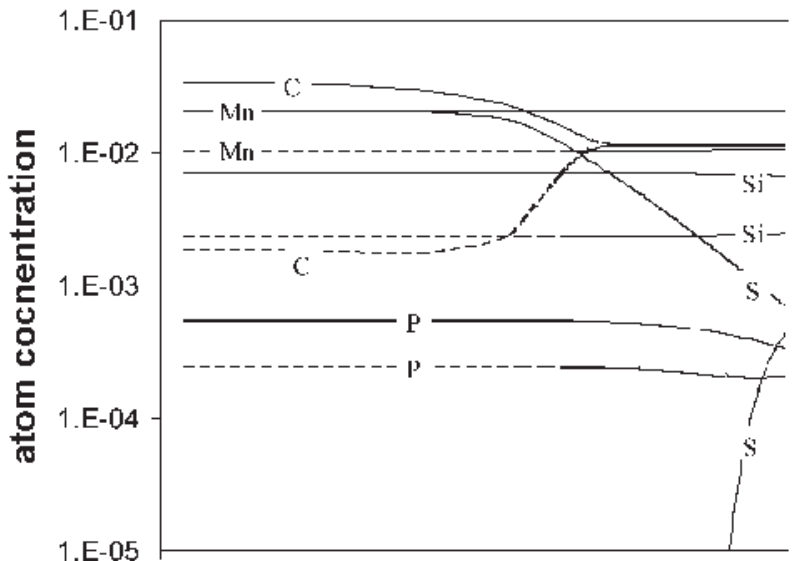

(a)

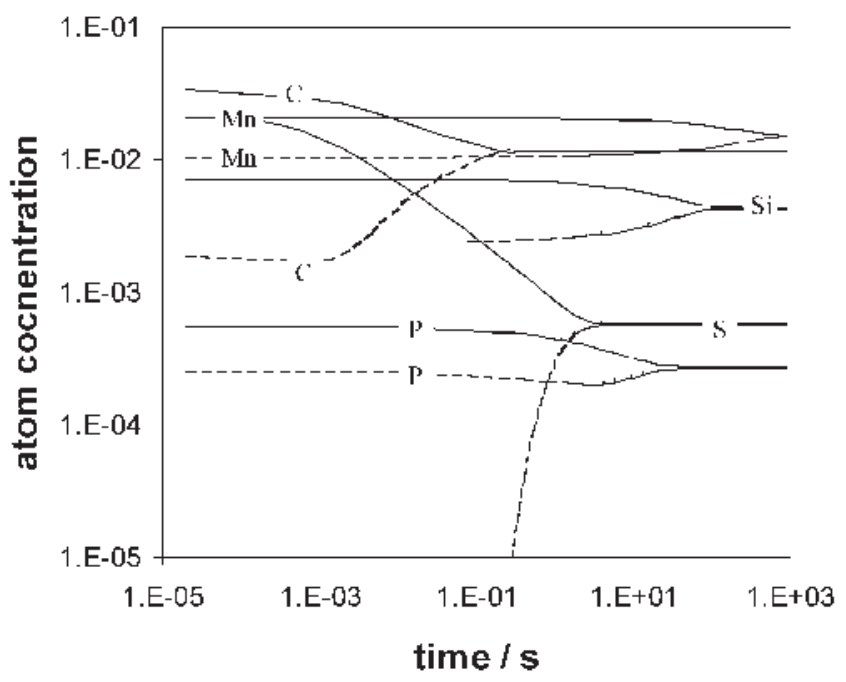

(b)

Fig. 7-Alloy 2 solute redistribution in nodes 0 (dotted line) and 50 (solid line) for (a) $1173 \mathrm{~K}$ and $(b) 1593 \mathrm{~K}$.

It is worth noting that some other criteria have been proposed for band prevention. Offerman et al. ${ }^{[5]}$ have approximated the distance over which carbon diffuses in the austenite as $d_{\mathrm{C}} \approx\left(D_{\mathrm{C}} t\right)^{1 / 2}$, where $D_{\mathrm{C}}$ is the diffusion coefficient of carbon in austenite and $t$ the period of time between the onset of the ferrite formation and the onset of the pearlite formation. They observed that $d_{\mathrm{C}}$ sharply increases around the temperature where bands appear $(963 \mathrm{~K})$ in alloy $3 \cdot{ }^{[5]}$ Although we did not employ this criterion, our method is consistent with it, as the diffusion of both carbon and substitutional solutes in austenite are calculated through Eq. [2], and thus the nodal composition variation with time is obtained, and the local driving force for ferrite nucleation calculated.

The calculations performed here demonstrate a strong link between alloy composition, heat treatment time, and temperature (leading to the flattening of concentration profiles), and microchemical segregation wavelength. Furthermore, it is now possible to predict the conditions under which ferrite/pearlite bands in steels may be eliminated. Alloy 3 calculations strongly suggest that some substitutional solutes such as Mo and Mn behave as "band stabilizers," while a decrease in microchemical segregation wavelength will speed up solute diffusion and 


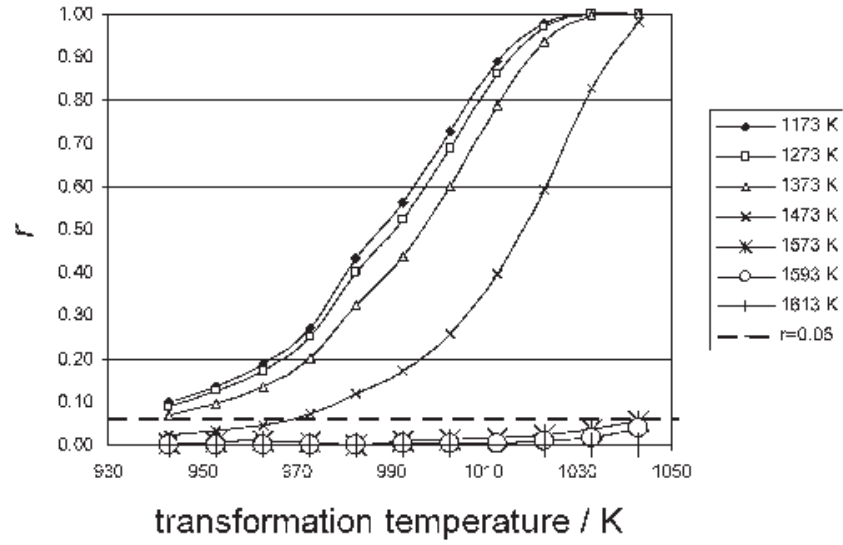

Fig. 8-Variation of $r$ with transformation temperature for alloy 2 heat treated at the indicated temperatures. The dotted line $(r=0.06)$ represents the limit under which bands disappear. ${ }^{[5]}$

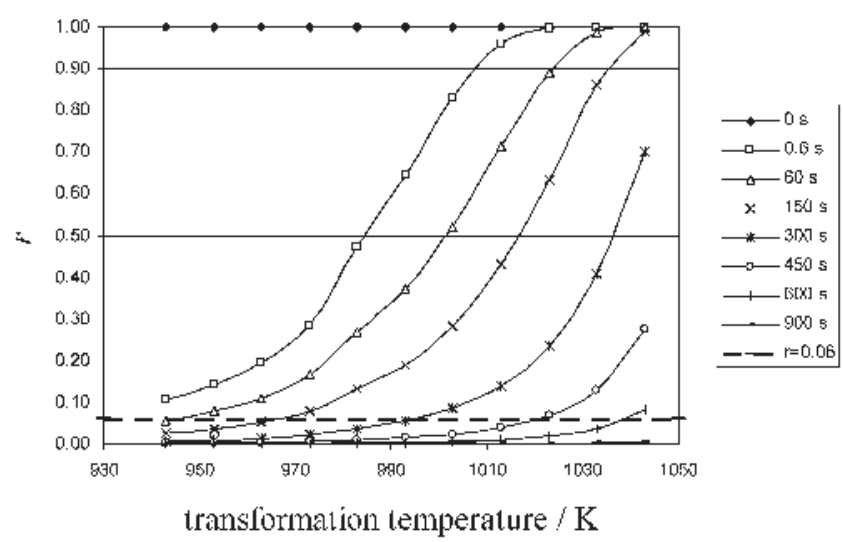

Fig. 9-Variation of $r$ with the transformation time for alloy 2 heat treated at $1593 \mathrm{~K}$. The dotted line $(r=0.06)$ represents limit under which bands disappear. ${ }^{[5]}$

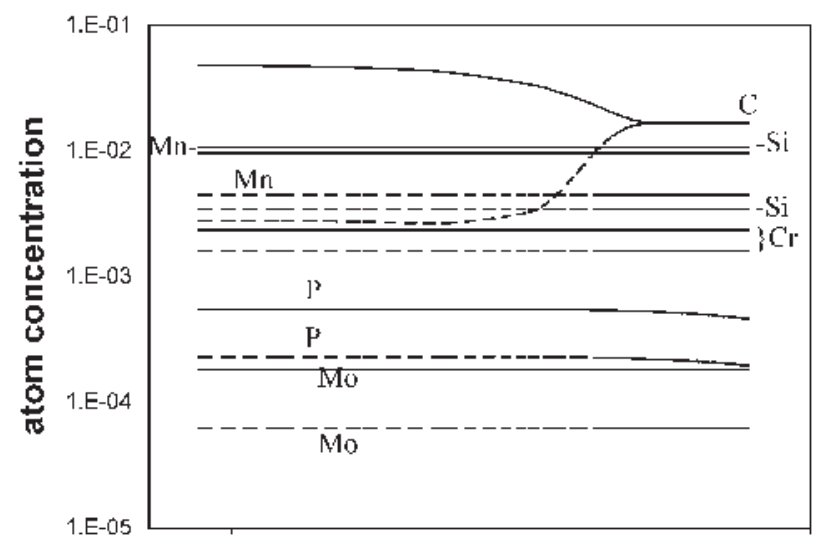

time / s

Fig. 10 - Component concentrations in nodes 0 (dotted lines) and 50 (solid lines).

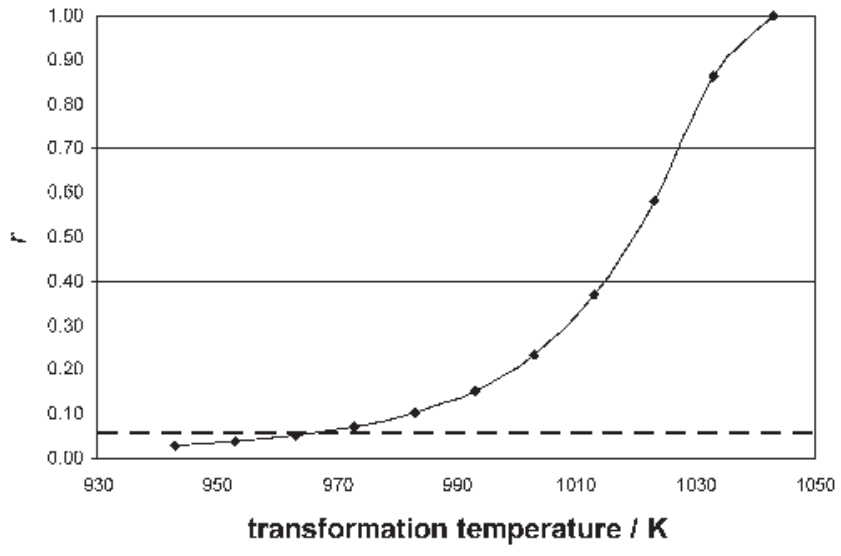

Fig. 11-Variation of $r$ with the transformation temperature for alloy 3 heat treated at $1173 \mathrm{~K}$. The dotted line $(r=0.06)$ represents the limit above which banding occurs. ${ }^{[5]}$

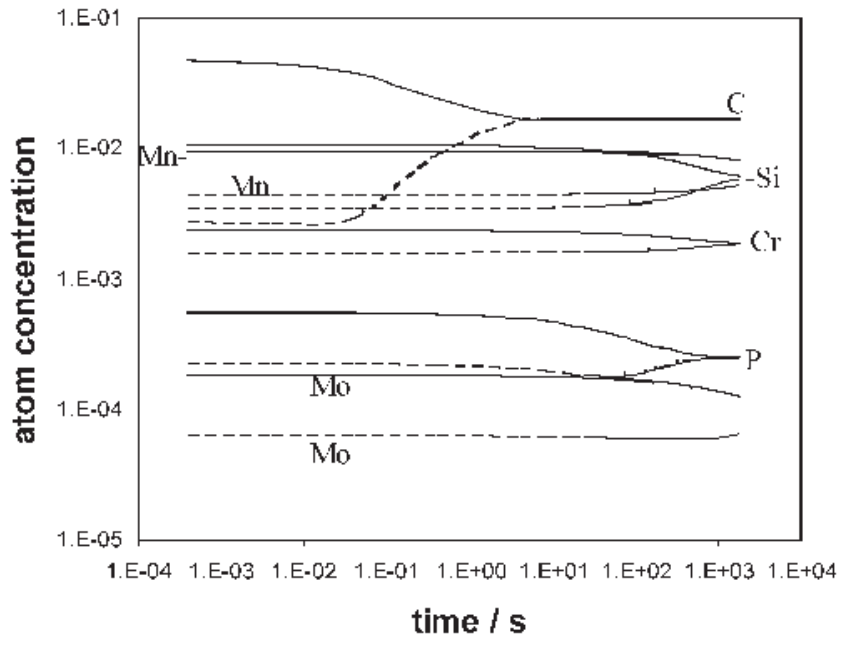

Fig. 12-Component concentrations in nodes 0 (dotted lines) and 50 (solid lines).

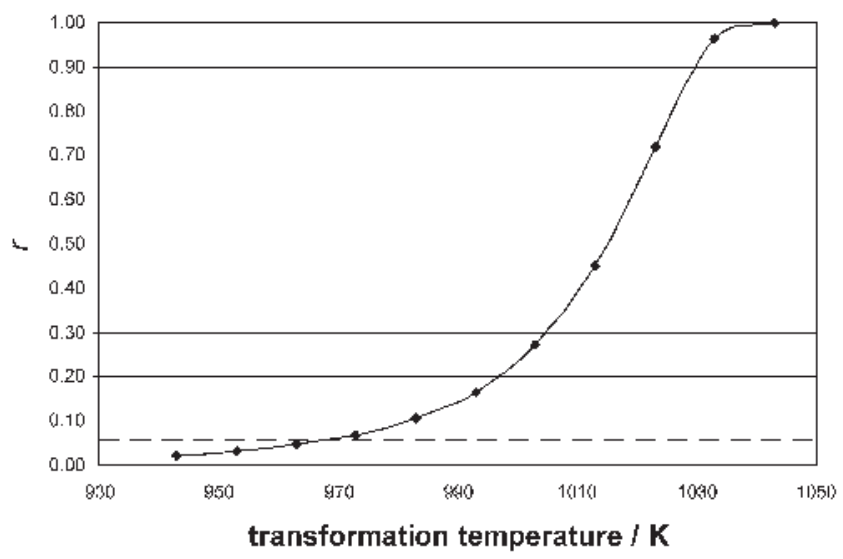

Fig. 13-Variation of $r$ with the transformation temperature for alloy 3 heat treated at $1613 \mathrm{~K}$. The dotted line $(r=0.06)$ represents the limit above which banding occurs. ${ }^{[5]}$ 
homogenization, through reducing $\Delta x$ in Eq. [2]. Further research using this model will allow us to quantitatively determine the effects that composition, microchemical segregation wavelength, heat treatment and transformation time, and temperature have on band prevention in general; these calculations would be of great use for the steel industry.

The necessity of using a scaling parameter of $\lambda \ll<$, which in the present work has been estimated as $\lambda=0.0015$, is well in agreement with previous work from Aaronson and co-workers ${ }^{[28,29,30]}$ and Offerman et al. ${ }^{[31]}$ This finding seems to indicate that crystallography must play a role in determining the critical nucleus shape and $\Delta G^{*} \cdot{ }^{[28,29,30]}$

The multiangle approach presented in this model (solidification, diffusion, and nucleation) can be further improved by adding the stages of ferrite/pearlite growth kinetics; this would precisely determine the configuration of the microstructure obtained after transformation and would validate the model. The inclusion of transformation kinetics will be dealt with in a forthcoming publication.

\section{CONCLUSIONS}

1. There is a relationship between the differences in ferrite/ pearlite nucleation rates across the microchemical bands and the ferrite/pearlite band formation. For differences in the nucleation rate $(r)$ lower than 6 pct, the formation of ferrite/pearlite bands can be prevented.

2. There is a marked tendency to decrease $r$ with an increase in austenitization time and temperature, but such a decrease can be hindered as segregation of components such as Mn or Mo are present.

3. The control of microchemical segregation wavelength is important for ferrite/pearlite band prevention; the lower it is, the faster is the solute homogenization and lowering of $r$.

4. The model outlined here can be applied in general for any steel where the phase composition and chemical potential variations with concentration are known. The general influence in band prevention of parameters such as heat treating time and temperature, transformation time and temperature, and microchemical segregation wavelength can be quantified.

\section{ACKNOWLEDGMENTS}

The authors are grateful for the financial support from the ECSC through the programme "Suppression of Banded
Structure and Refinement of the Microstructure of High Strength Cold Rolled Steels by Optimisation of Hot Rolling and Cold Rolling Path."

\section{REFERENCES}

1. J.D. Verhoeven: J. Mater. Engr. Performance, 2000, vol. 9, pp. 286-96.

2. S.W. Thompson and P.R. Howell: Mater. Sci. Technol., 1992, vol. 8, pp. 777-84

3. P.G. Bastien: J. Iron Steel Inst., 1957, pp. 281-91.

4. T.A. Kop, J. Sietsma, and S. van der Zwaag: Mater. Sci. Technol. 2001, vol. 17, pp. 1569-74.

5. S.E. Offerman, N.H. van Dijk, M.T. Rekveldt, J. Sietsma, and S. van der Zwaag: Mater. Sci. Technol., 2002, vol. 18, pp. 297-303.

6. MTDATA: Metallurgical and Thermochemical Databank, National Physical Laboratory, Teddington, Middlesex, United Kingdom, 1995.

7. J.S. Kirkaldi and D.J. Young: Diffusion in the Condensed State, Institute of Materials, London, 1987.

8. R.A. Tanzillini and R.W. Heckel: Trans. TMS-AIME, 1968, vol. 242, pp. 2313-21.

9. L.C. Brown and J.S. Kirkaldi: Trans. TMS-AIME, 1964, vol. 230, pp. 223-26.

10. J. Ågren: Scripta Metall., 1986, vol. 20, pp. 1507-10.

11. K. Nohara and K. Hirano: Nippon Kinzoku Gakkai-shi (J. Jpn. Inst. Met.), 1976, vol. 40, pp. 1053-61.

12. P.J. Alberry and C.W. Haworth: Met. Sci., 1974, vol. 8, pp. 407-12.

13. M.A. Krishtal and A.P. Mokrov: Zaved. Lab., 1967, vol. 33, pp. 827-29.

14. T. Eguchi, Y. Iijima, and K. Hirano: Cryst. Lattice Defects, 1973, vol. 4, pp. 265-74.

15. A.M. Huntz, P. Guiraldenq, M. Aucouturier, and P. Lacombe: Mem. Sci. Rev. Met., 1969, vol. 66, pp. 85-104.

16. A.W. Bowen and G.M. Leak: Metall. Trans., 1970, vol. 1, pp. 1695-700.

17. K. Nohara and K. Hirano: Suppl. Trans. Iron Steel Inst. Jpn., 1971, pp. 1267-73.

18. C. Wells and R.F. Mehl: Trans. AIME, 1941, vol. 145, pp. 315-28.

19. J. Fridberg, L.E. Torndahl, and M. Hillert: Jernkont. Ann., 1969, vol. 153, pp. 263-76.

20. P.L. Gruzin and V.V. Mural: Fiz. Metallov Metalloved., 1963, vol. 16, pp. 551-56.

21. G. Seibel: Comput. Rend. Acad. Sci., 1963, vol. C256, pp. 4661-64.

22. S.J. Wang and H.J. Grabke: Z. Metallkd., 1970, vol. 61, pp. 597-603.

23. G. Seibel: Mem. Sci. Rev. Metall., 1964, vol. 61, pp. 413-34.

24. W. Krass: Neue Hutte, 1969, vol. 14, p. 247.

25. Y. van Leeuwen, S. Vooijs, J. Sietsma, and S. van der Zwaag: Metall. Mater. Trans. A, 1998, vol. 29A, pp. 2925-31.

26. P.J. Clemm and J.C. Fischer: Acta Metall, 1955, vol. 3, p. 70.

27. R.A. Grange: Metall. Trans., 1971, vol. 2, pp. 417-26.

28. M. Enomoto and H.I. Aaronson: Metall. Trans. A, 1986, vol. 17A, pp. $1385-97$

29. M. Enomoto, W.F. Lange III, and H.I. Aaronson: Metall. Trans. A, 1986, vol. 17A, pp. 1399-407.

30. W.F. Lange III, M. Enomoto, and H.I. Aaronson: Metall. Trans. A, 1988, vol. 19A, pp. 427-40.

31. S.E. Offerman, N.H. van Dijk, J. Sietsma, S. Grigull, E.M. Lauridsen, L. Marguiles, H.F. Poulsen, M. Th. Rekveldt, and S. van der Zwaag: Science, 2002, vol. 298, pp. 1003-05. 